\title{
Survey of the general public to determine perceptions and precautions taken when choosing personal service establishments
}

\author{
Bobbie Lojpur ${ }^{1}$, Helen Heacock ${ }^{2}$ \\ ${ }^{1}$ Lead Author, B.Tech Student, School of Health Sciences, British Columbia Institute of Technology, 3700 Willingdon Ave, Burnaby, BC V5G 3H2 \\ ${ }^{2}$ Supervisor, School of Health Sciences, British Columbia Institute of Technology, 3700 Willingdon Ave, Burnaby, BC V5G 3H2
}

\section{Abstract:}

Objective: Personal service establishments (PSEs) include tattoo parlors, piercing shops, and beauty salons. Many of the services provided have potential to spread diseases due to the invasive nature and possibility of cross contamination if sanitation procedures are not followed. Potential infections such as nontuberculosis mycobacterium, staphylococcus aureus and blood borne infections such as Hepatitis and HIV are possible. There is concern among Environmental Health Officers (EHOs), and professionals in the industry regarding the lack of regulations and training of employees within the industry. This study investigated the criteria and safety measures the public takes when determining which personal service establishment they receive treatments from.

Methods: A questionnaire was administered online through social media and Google Docs. Inferential statistical analyses determined if there were associations between certain demographic information and the responses given from participants.

Results: There were six associations that were found when comparing demographic groups (age, gender and education) with the survey questions. A p value of 0.021008 was found in the association between age and perceived level of regulation of the industry, a $\mathrm{p}$ value of 0.014407 was found in the association between education and asking about sanitation procedures before an appointment, and a p value of 0.008668 was found in the association of education and if participant asks for references. In addition, $\mathrm{p}$ values of 0.028151 and 0.011739 with associations of gender and education, respectively, and the participants perceived ability to recognize bad practices during a procedure. Finally, a p value of 0.029766 was found in the association of gender and participants interest in additional information about how to choose an establishment.

Conclusions: There were six hypotheses that resulted in statistically significant associations between a demographic and the survey question. Over 30 year olds chose PSEs were minimally regulated, while higher education groups were more likely to ask about sanitation and for references before a procedure. Females and people with some post secondary education felt they were more able to recognize bad practices during a procedure. Finally, females were most interested in additional information about PSEs.

Keywords: Personal Service Establishments, PSEs, PSE Guidelines, Staphylococcus aureus, Nontuberculosis mycobacterium, Hepatitis, HIV, BeautySafe.

\section{Literature Review}

Today's society constantly bombards its citizens with advertisements and services available to better ourselves, whether it's the latest beauty craze or body modification, a new service is popping up on every city block. They are attractive services because they are selling an improved version of yourself, with the convenience of someone else performing the labor, just sit down and relax. However, these services can be very risky in nature and the advertisements do not inform the public of any "behind the scenes” processes that are necessary for the service to be safe.

Personal service establishments (PSEs) include tattoo parlors, piercing shops, and beauty salons. Many of the services provided have potential to spread diseases due to the invasive nature and possibility of cross contamination if sanitation procedures are not followed. Some of the services may seem quite routine, for instance a manicure or pedicure, but it can easily turn into a situation where pathogens encounter an open wound or cut causing an infection. Despite being a high risk establishment, environmental health officers have few regulations to work with to enforce sanitary practices. When compared with the Food Premise Regulations, used in restaurant inspections, the legislation for personal service establishments are minimal (Public Health Act, 2008).
There is concern among Environmental Health Officers (EHOs), and professionals in the industry regarding the lack of regulations and irregularities between provinces and other countries outside of

Canada (Rideout, 2010). The legislation may be lacking and time consuming to introduce new laws due to government processes, but there are still methods that EHOs can take to protect the public. EHOs can use their knowledge and experience to educate the public to empower them to have more control over their health when entering these establishments. However, the current state regarding the public's knowledge and interest in the dangers and risks involved in PSEs is unclear. This research project investigated criteria people use to determine which PSE to visit and what precautions, if any, are taken upon arrival. The results could be useful for EHOs to focus their attention on groups who are the least likely to take any safety measure of their own when entering a PSE and teach them how to make informed, safe decisions regarding personal services.

\section{$\underline{\text { Personal Service Establishments and Legislation }}$}

A personal service establishment, as defined by the Regulated Activities Regulations of the Public Health Act, "means an establishment in which a person provides a service to or on the body of another person, and includes a barbershop, beauty parlor, health spa, massage parlor, tattoo shop, sauna and steam bath ” (Public Health Act, 2008). This includes services such as acrylic nails, body branding, body piercing, face painting, 
manicure/pedicures, mud baths, sauna, shavings, tanning, tattooing, waxing and others (Public Health Act, 2008).

Personal service establishments clearly cover a wide range of procedures ranging in risk for contracting a communicable disease. Although there are many high risks and invasive procedures, the legislation, which is enforceable by Environmental Health Officers, is minimal. The only regulations regarding PSEs fall under the Regulated Activities Regulations and are as follows:

\section{"Water supply required}

An operator of a personal service establishment must not operate the establishment unless there is, on the premises of the establishment,

- An adequate supply of hot and cold water at all times for operating and cleaning purposes, and

- An adequate and conveniently located hot and cold water hand washing facility” (Public Health Act, 2008)

The other regulations listed in this section are regarding tanning salons, detailing the age limitations and mandatory signage for this type of establishment. The associated guidelines called Guidelines for Personal Service Establishments, are much more comprehensive. They cover topics such as premises and general operation, equipment, infection control, sanitation and disinfection, other materials, and personnel (British Columbia Ministry of Health, 2013). Each section covers in detail the best practices to prevent a health hazard from occurring. Health hazards are included in the Public Health Act, and an environmental health officer can issue orders in PSEs based on the presence of a health hazard.

\section{$\underline{\text { Environmental Health Officers and Issuing Orders }}$}

In order for EHOs to issue orders in PSEs, they must do so under the Public Health Act and use the definition of a "health hazard. From the Act, a "health hazard" is defined as

“(a) A condition, a thing or an activity that

(i) Endangers, or is likely to endanger, public health, or

(ii) Interferes, or is likely to interfere, with the

suppression of infectious agents or hazardous agents, or

(b) A prescribed condition, thing or activity, including a

prescribed condition, thing or activity that

(i) Is associated with injury or illness, or

(ii) Fails to meet a prescribed standard in relation to

health, injury or illness” (Public Health Act, 2008)

\section{Guidelines}

As a supplement to the regulations, there are various guidelines available for operators of PSEs to follow for best practices (British Columbia Ministry of Health, n.d.). The following are existing guidelines: Guidelines for Personal Service Establishments, Guidelines for Personal Services offered at Tradeshows (new as of September 2013), Best Practice Guidelines for Cleaning, Disinfection and Sterilization of Critical and SemiCritical Medical Devices, Guidelines for Tattooing, Guidelines for Piercing and Guidelines for Laser Hair Removal (British Columbia Ministry of Health, n.d.).
These guidelines provide a framework for these establishments on best practices and sanitation requirements, some even in specific industries (British Columbia Ministry of Health, 1999). However, there are not guidelines for all types of establishments (ex. Nail salons, hair salons). There are such a wide variety of services that it is difficult for policy makers and Health Authorities to make guidelines for each type of procedure. It is important to note that guidelines are not enforceable by EHOs. The lack of mandatory regulations leaves room for error by workers in PSEs. In comparison, The Food Premise Regulations has a lengthy list of enforceable regulations that allows EHOs to have a standardized framework to base an inspection on (Public Health Act, 2008).

\section{Training and Employees in the PSE industry}

Another aspect of personal service establishments that varies from place to place is the level of training required before they are able to practice. There are no minimum educational requirements in the industry, whether invasive body modification is happening or a manicure. In comparison with the food service industry, the regulations state that at least one person on site must be a FoodSafe Certificate holder to ensure an informed person is on staff (Public Health Act, 2008). From 1994 to 2003, British Columbia had a Cosmetologists Act, which regulated the industry and had enforceable standards workers had to abide by (Cosmetologists Act, 1996). Since deregulation of this Act in 2003, there has been no legislative replacement or requirements in PSEs, a tattoo artist does not need specific training to open their own parlor, nor do they need a license to practice (Public Health Act, 2008). There are programs such as BeautySafe (similar to FoodSafe), although these courses are voluntary, unlike FoodSafe, which is a requirement in the Food Premise Regulations (BeautySafe, n.d.) (Public Health Act, 2008).

The general public may be very unaware of the legislative state regarding personal service establishments and put their trust in possibly competent, or incompetent employees. Some workers may be very educated and trustworthy, while some may be less interested or concerned with sanitary practices. Assessing the establishment and asking appropriate questions could save members of the public from making uninformed choices when receiving a dangerous treatment such as body modification or tattoos. When entering these establishments, the client should feel confident that tools and equipment are clean and that the employees are using them in the correct manner, and knowing how to deal with situations that break the skin or when bodily fluids are involved (Johnson et at., 2001).

Studies have shown that workers have admitted to not abiding by proper sanitation standards as listed in the guidelines. Nail technicians admitted to inconsistent and non-use of gloves, and inconsistent sanitation of their equipment and tools (Johnson et al., 2001). This raises a major distress in public health since blood-borne diseases are potentially spread via tools that have been used on multiple people. An additional public health concern that was identified through survey questions of the nail technicians was the disposal of sharps. Razor blades used on callouses were reused by one third of technicians in this study and disposed of them in the garbage, not using a sharps container (Johnson et al., 2001). 
Another survey given to beauty technicians questioned how well they understood the transmission of Hepatitis C and HIV. Approximately $80 \%$ of the workers stated they are exposed to blood, and most stated their training on safety precautions as “common sense” (Asif \& Ahmad, 2011). These workers are frequently performing procedures that expose them to blood, when they are unclear about transmission of disease and safety procedures; they may mishandle an accident and cause a health hazard (Asif \& Ahmad, 2011). The public needs to be aware of the fact that the industry does not have specific requirements for training and they need to be aware of risks involved at personal service establishments.

\section{$\underline{\text { Outbreaks }}$}

Outbreaks have continued to happen in Canada and all over the world from personal service establishments and many go unreported due to difficulty in assigning cause and effect. Some infections like nontuberculosis mycobacterium may be difficult to diagnose, due to similar signs and symptoms of allergic reactions (LeBlanc, Hollinger, \& Klontz, 2012). These outbreaks should be taken as seriously as any foodborne illness outbreak from a restaurant, since a communicable disease such as HIV can be spread from person to person and infect many lives other than just the person who received a the service. Furthermore unsanitary procedures are being offered to the public.

\section{Staphylococcus aureus and MRSA}

A concern regarding personal service establishments is contracting a skin infection such as staphylococcus aureus, or an antibiotic resistant MRSA infection. There have been reports regarding MRSA infections in patients who received tattoos from an unlicensed tattoo artist who did not practice proper sanitation procedures (Superbug, 2006). Again, this raises the point that people interested in tattoos need to assess the standards of practice in these establishments. MRSA infections are a growing problem in communities due to them being difficult to cure (Superbug, 2006). Furthermore, this may cause a greater public health concern by spreading MRSA to members of the public who are unknowingly exposed, thereby causing a much larger outbreak.

\section{Nontuberculosis mycobacterium}

Nontuberculosis mycobacterium has been identified as the cause of infections from a variety of procedures in personal service establishments, from tattoo ink to footbaths during pedicures. Patients will often notice red papules where the contaminated ink was injected into the skin (LeBlanc, Hollinger, \& Klontz, 2012). Certain ink colors tattoo artists use need to be diluted in order to get the right shading effect on the client (Rodriguez-Blanco et al., 2011). However, it has been found that if the water used to dilute the ink is not distilled, it can harbor the pathogen (RodriguezBlanco et al., 2011). Further complications regarding MRSA are then possible, creating a much harder issue to treat (LeBlanc, Hollinger, \& Klontz, 2012). Even if a tattoo artist follows hygienic practice, but is unaware of how to safely handle and dilute ink, nontuberculosis mycobacterium infections are a potential risk (LeBlanc, Hollinger, \& Klontz, 2012).

To try to determine when ink becomes contaminated, one study tested ink bottles that had been opened and exposed to the ambient atmosphere from a range of two weeks to several months. The results showed the ink was sterile (Kluger, Terru \& Godreuil,
2011). This led researchers to investigate what the source of contamination in these products was and found that microbiological introduction most likely came from improperly cleaned tools, and poor sanitation (Kluger, Terru \& Godreuil, 2011).

The consequences of a nontuberculosis mycobacterium infection may be quite serious and range from a skin biopsy, weeks of recovery, and future complications with MRSA. Education of both the tattoo artist and the public interested in tattoos need to be addressed to reduce negative implications and quicker diagnoses to prevent escalation of the infection (LeBlanc, Hollinger, \& Klontz, 2012). In addition, if a nonmycobacterium infection is possible, it may be a sign that tattooing practices are not perfectly sterile, increasing the threat of contracting a much more serious disease like Hepatitis or HIV.

Mycobacterium fortuitum infections are also associated with footbaths used during pedicures in nail salons. Mycobacterium fortuitum is a nontuberculous type mycobacterial infection that is ubiquitous in soil and water and able to grow rapidly (Winthrop et al., 2004). A study in California tested footbaths, and nearly all tested were positive for this pathogen. Even baths that the filter appeared clean tested positive, which stresses the importance of proper disinfection not just removal of visible debris (Vugia et al., 2005). When workers were asked about maintenance, they reported that some of the footbaths had never been cleaned. It is important that clients understand the risk factors involved and what equipment may be a source of contamination in salons so they can ask appropriate questions to protect their health (Vugia et al., 2005).

\section{Hepatitis B, C and HIV}

Personal service establishments that offer invasive procedures such as piercings, tattoos and body modifications can increase the client's risk of contracting a blood-borne virus such as hepatitis or HIV. These diseases may also be spread through bodily fluids from sexual intercourse, injection drug use, and mother to baby and individuals may not show signs and symptoms until years later, increasing the potential to unknowingly spread the disease (Garland et al., 2006). Many of these body modification procedures provide the opportunity to be exposed to blood and it is up to the employee to deal with the hazardous situation in a sanitary manner and follow hygienic procedures (Asif \& Ahmad, 2011). Survey studies of workers have shown that knowledge is inconsistent as well as procedures and safety precautions when dealing with exposure to blood (Asif \& Ahmad, 2011).

Sterilization procedures were not always followed as well as employee hygiene practices like washing hands and wearing gloves (Asif \& Ahmad, 2011). The lack of knowledge, and inconsistent sanitary behavior intensifies the risk of spreading communicable disease such as Hepatitis B, Hepatitis C and HIV from personal service establishments.

\section{$\underline{\text { Public and demographics }}$}

Since there is such a range of services that are offered, a wide demographic regarding who visits personal service establishments is possible. Certain demographic groups may be more likely to receive certain treatments, such as women of all ages receiving nail treatments such as manicures and pedicures. 
Demographic groups that are interested in body modification procedures have been changing over time. Initially these types of behaviors were more prevalent in high-risk groups like prisoners, street youth, HIV patients and sex workers (Siavash et al., 2012). Over time, the group of individuals interested in tattoos and piercing has shifted to more conservative demographics (Siavash et al., 2012). A study in Quebec, Canada surveyed high school youth regarding attitudes toward body modification. They found that interest in these activities increased with age and there were some gender differences in which category of modification they would receive (girls interest in tattoo and piercing, boys in multiple tattoos) (Deschesnes, Demers \& Fines, 2006).

Another study of Italian youth revealed that most who had undergone a procedure were not significantly concerned with associated health risks (Cegolon et al., 2010). It was discovered that students who viewed body modification favorably were less likely to use a professional service. Body modification usually comes with an age restriction of eighteen years or older, which may force interested youth whose parents do not approve, to perform procedures on their own or illegally (Cegolon et al., 2010). It is troubling that youth are unconcerned with risks involved and may take drastic actions or seek poorly operated establishments to acquire body modification. This may be an area where EHOs can focus educational materials to youth to ensure they are taking a safe approach to body modification.

\section{Evaluating Personal Service Establishments}

The public may not evaluate personal service establishments based on criteria that an EHO would. They may be inclined to visit a specific PSE because of an inexpensive price for the service, proximity to home, referrals from friends, or because of a tattoo artists reputation regarding art work, not cleanliness or safety. Some PSEs may be strictly regulated internally and comply with guidelines, and others may be poorly operated. Since the regulations are so vague and minimal, there are knowledge gaps regarding infection control and mandatory behaviors throughout the industry (Rideout, 2010). An establishment may appear clean on the surface, but if sanitation practices are not being consistently followed, this will not appear as a risk factor unless workers are questioned, to reveal a lack of knowledge. EHOs can work with the public to educate them on asking critical questions to identify a well-operated establishment, and not get distracted by advertising tactics.

Survey studies of workers in the industry have highlighted the fact that the knowledge base is inconsistent ranging in intensity of procedures, from nail technicians to tattoo artists and body piercers (Oberdorfer et al., 2003). Although some people may not be too concerned with a treatable infection such as a nontuberculosis mycobacterium infection on their legs, it raises the issue that if an infection of this nature is possible, so is transmission of much more serious diseases like HIV. Many seemingly routine procedures such as manicures, pose risk for accidental cuts and bleeding. If the technician is not careful and misusing single use disposable equipment, there can be an elevated risk of contracting a blood-borne infection (HarrisRoberts et al., 2013). Since studies have indicated the inconsistent knowledge base coupled with the fact that EHOs may only inspect on a yearly basis with minimal regulations, it is important that the public is able to critically assess these businesses for themselves and understand the whole dynamic of the personal service establishment industry. (Oberdorfer et al., 2003).

\section{$\underline{\text { Research Question }}$}

The public should be comfortable with, and able to ask appropriate questions to PSE workers before procedures. If the public can critically assess the premise and look for red flags they can choose an establishment based on the same criteria an environmental health officer would inspect on, and decrease their risk of contracting a disease or infection. This study will investigate the criteria and safety measures the public takes when determining which personal service establishment they receive treatments from.

\section{Methods and Materials:}

\section{Description of materials used:}

A survey was conducted in British Columbia in 2013-2014 to establish the criteria the public uses, if any, when selecting and visiting a PSE. A structured questionnaire was distributed online, through Google Docs (Google Docs, 2013). The survey was advertised through social media sites to contacts who were encouraged to forward the survey to their contacts and gain responses through the snowball effect. The body of the questionnaire focused on asking what precautions have been taken in regards to choosing an establishment and about awareness during services. Materials used included a computer with internet, cover letter, consent form, questionnaire, Microsoft Excel 2011 (Microsoft, 2011), Microsoft Word 2011 (Microsoft, 2011), NCSS 9 (Hintz, 2013), Google Docs (Google Docs, 2013), and Facebook (Facebook, 2013).

\section{Standard Method:}

The standard method that was utilized in this study consisted of administering the survey online through email contacts, and social media platforms. Participants were asked to forward the survey to their contacts to increase response size and randomized populations that are from various backgrounds and demographics. The survey consisted of close ended questions to reduce ambiguity in participant responses. Survey responses were gathered and organized using Microsoft Excel (Microsoft, 2011). The results were analyzed using a chi-square test in statistical software NCSS (Hintz, 2013).

\section{Reliability and Validity:}

This study had high reliability because the methodology used standard forms and documents that all participants received and could be used again with a different sample population. All questionnaires can be administered in the same manner (online) and results interpreted in the same manner with a chi-square test (Heacock and Sidhu, 2013a). Internal validity was taken into account by designing survey questions to be close ended, removing the opportunity for ambiguous responses. Including all demographics that represent the general population instead of a select group of people can increase external validity. 


\section{Inclusion and Exclusion criteria:}

Inclusion criteria involved all members of the public in British Columbia, who have visited a personal service establishment. Exclusion criteria were members of the public who have not visited a personal service establishment.

\section{Ethical considerations:}

The researcher approached ethical issues because it was a human based study, by using a cover letter and consent form that was supplied along with the questionnaire. These documents informed the participant about who was conducting the research, why and how the information would be used and how to withdraw from participating. The questionnaire itself was written in a way to avoid any ethical issues and submitted to course instructors for ethics approval (Helen Heacock and Bobby Sidhu). A pilot study was conducted to correct for any miscommunication or unclear aspects of the survey.

\section{Results}

\section{$\underline{\text { Inferential Statistics }}$}

A sample question from the survey was analyzed with statistical software NCSS. Survey question five asked participants, "Do you feel that you would be able to distinguish and recognize bad practices during a personal service?” with response options a) always b) sometimes c) never.

Ho: There is no association between gender and whether or not participants feel they can recognize and distinguish bad practices during a procedure.

Ha: There is an association between gender and whether or not participants feel they can recognize and distinguish bad practices during a procedure.

In a chi square analysis, Ho is rejected when $\mathrm{p}=0.05$. The $\mathrm{p}$ value $=0.028151$. Since $0.028151<0.05$, the Ho is rejected and the Ha is accepted. This can be interpreted as an association between gender and whether or not participants feel they can recognize bad practices during a procedure with females appearing to be more likely to think they are able (Heacock and Sidhu, 2013c). There was no beta error, although there was a possibility of alpha error. An alpha error could exist if the significance level changed to $\mathrm{p}<0.01$, the $\mathrm{p}$ value from the statistical test would be greater than the cutoff and not produce significant results (Heacock and Sidhu, 2013b).

The survey results and chi square analysis of the data resulted in six hypotheses where the null hypothesis was rejected and the alternate hypothesis was accepted. Table 1 shows a summary of the results. The same procedure was used as in the sample previously shown for each of the remaining survey.

\section{Descriptive Statistics}

The survey questions were also analyzed in terms of their descriptive statistics to analyze how many responses were collected in each of the categories and looked at for general trends amongst respondents. The general trends for questions regarding if participants asked about sanitation before, references and training, the majority or responses were "never.” Other interesting findings were in the questions about awareness during procedures and whether the participant felt they could distinguish if the employee was following hygienic behaviors, the majority of people were in the "always" or "sometimes" categories. Finally, the responses to additional information shows that most of the people who took the survey were interested and willing to learn more about personal service establishments.

\section{Discussion}

This study was conducted to gain further insight into the precautions people take when choosing and visiting a personal service establishment, if any are taken at all. The results did show statistically significant findings and associations. First, there was an association between age and how regulated the participant thought the industry was. The over 30 year olds answered that PSEs are "minimally regulated," which would be the correct choice. However, the results also showed that most 21-30 year olds believed it was "moderately regulated." As previously discussed in the literature review, the regulations that public health inspections have to inspect these facilities on is very minimal. This shows that the public is misinformed about the state of the industry and potentially how much attention they should pay when choosing an establishment, especially when invasive procedures are being done.

When participants were asked if they ever ask the establishment or employee about the sanitation procedures before booking an appointment, the results showed there was a significant association between education and their willingness to ask these questions, with people with a bachelors degree, trade school or higher being more diligent in this area. However, the majority of responses were in the "Never" or "Sometimes" category. Despite their level of education and potentially knowing about communicable diseases, more educated people still do not ask questions regarding sanitation before an invasive procedure for their own protection. Similarly, when responding to question three regarding if they asked for references, there was a statistically significant response with education. Again, people with a bachelors degree or higher were more likely to "always" ask compared to the other education groups, but the majority of responses were in the "Never" category.

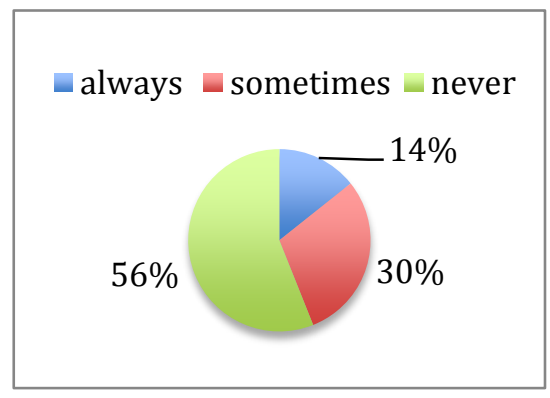
Figure 1 Percentage of participants who ask about sanitation before a procedure

There were two statistically significant responses regarding question five about the participants' perceived ability to recognize bad practices during a procedure. Both the gender and education demographic showed significant results. Most females felt they can "always" or "sometimes" notice, and people with some 


\begin{tabular}{|c|c|c|c|c|}
\hline Question & \multicolumn{2}{|c|}{ Demographic \& P value } & Hypothesis & Result and Association \\
\hline Level of Regulation? & $\begin{array}{c}\text { Age } \\
\text { Gender } \\
\text { Education }\end{array}$ & $\begin{array}{l}0.021008 \\
0.209755 \\
0.061131\end{array}$ & $\begin{array}{l}\text { Reject Ho } \\
\text { Accept Ho } \\
\text { Accept Ho }\end{array}$ & $\begin{array}{l}\text { There is an association between age and how regulated } \\
\text { PSEs are perceived to be (Over } 30 \text { yr. olds \& minimally } \\
\text { regulated). }\end{array}$ \\
\hline Ask about Sanitation? & $\begin{array}{c}\text { Age } \\
\text { Gender } \\
\text { Education }\end{array}$ & $\begin{array}{l}0.608542 \\
0.936142 \\
0.014407\end{array}$ & $\begin{array}{l}\text { Accept Ho } \\
\text { Accept Ho } \\
\text { Reject Ho }\end{array}$ & $\begin{array}{l}\text { There is an association between education and if they ask } \\
\text { about sanitation before an appointment (Higher education } \\
\text { \& more likely to ask). }\end{array}$ \\
\hline Ask for References? & $\begin{array}{c}\text { Age } \\
\text { Gender } \\
\text { Education }\end{array}$ & $\begin{array}{l}0.790824 \\
0.718349 \\
0.008668 \\
\end{array}$ & $\begin{array}{l}\text { Accept Ho } \\
\text { Accept Ho } \\
\text { Reject Ho }\end{array}$ & $\begin{array}{l}\text { There is an association between education and if the } \\
\text { participant asks for references (Higher education \& more } \\
\text { likely to ask). }\end{array}$ \\
\hline Ask about training etc.? & $\begin{array}{c}\text { Age } \\
\text { Gender } \\
\text { Education }\end{array}$ & $\begin{array}{l}0.246095 \\
0.804635 \\
0.418481\end{array}$ & $\begin{array}{l}\text { Accept Ho } \\
\text { Accept Ho } \\
\text { Accept Ho }\end{array}$ & No associations \\
\hline Recognize bad practices? & $\begin{array}{c}\text { Age } \\
\text { Gender } \\
\text { Education }\end{array}$ & $\begin{array}{l}0.239056 \\
0.028151 \\
0.011739\end{array}$ & $\begin{array}{l}\text { Accept Ho } \\
\text { Reject Ho } \\
\text { Reject Ho }\end{array}$ & $\begin{array}{l}\text { There is an association between gender and education and } \\
\text { if the participant felt they could recognize bad practices } \\
\text { during procedures (Female/Some Post Secondary } \\
\text { education \& more able to recognize behavior). }\end{array}$ \\
\hline $\begin{array}{l}\text { Watch for hygienic } \\
\text { practices during } \\
\text { procedure? }\end{array}$ & $\begin{array}{c}\text { Age } \\
\text { Gender } \\
\text { Education }\end{array}$ & $\begin{array}{l}0.304885 \\
0.109801 \\
0.082938\end{array}$ & $\begin{array}{l}\text { Accept Ho } \\
\text { Accept Ho } \\
\text { Accept Ho }\end{array}$ & No associations \\
\hline $\begin{array}{l}\text { Appropriate to ask } \\
\text { questions? }\end{array}$ & $\begin{array}{c}\text { Age } \\
\text { Gender } \\
\text { Education }\end{array}$ & $\begin{array}{l}0.968957 \\
0.087600 \\
0.101382\end{array}$ & $\begin{array}{l}\text { Accept Ho } \\
\text { Accept Ho } \\
\text { Accept Ho }\end{array}$ & No associations \\
\hline Ever felt at risk? & $\begin{array}{c}\text { Age } \\
\text { Gender } \\
\text { Education }\end{array}$ & $\begin{array}{l}0.418405 \\
0.379469 \\
0.168223\end{array}$ & $\begin{array}{l}\text { Accept Ho } \\
\text { Accept Ho } \\
\text { Accept Ho }\end{array}$ & No associations \\
\hline $\begin{array}{l}\text { Additional information } \\
\text { beneficial? }\end{array}$ & $\begin{array}{c}\text { Age } \\
\text { Gender } \\
\text { Education }\end{array}$ & $\begin{array}{l}0.324246 \\
0.029766 \\
0.948419\end{array}$ & $\begin{array}{l}\text { Accept Ho } \\
\text { Reject Ho } \\
\text { Accept Ho }\end{array}$ & $\begin{array}{l}\text { There is an association between gender and if the } \\
\text { participant feels that additional information would be } \\
\text { beneficial to them (Female \& more interest in info.). }\end{array}$ \\
\hline
\end{tabular}

postsecondary education responding most frequently with "always", followed by bachelor degree or higher responding as "sometimes.” Interestingly in this category, all demographic groups showed confidence in being able to secondary education responding most frequently with "always”, followed by bachelors degree or higher responding as "sometimes.” Interestingly in this category, all demographic groups showed confidence in being able to distinguish a bad practice.

Lastly, there was an association between gender and the participants' interest in additional information about how to choose a PSE, with females showing the most interest. Overall, $89 \%$ of respondents were interested in more information. This is an important point for EHOs to take note of. The public is interested in learning more and would potentially use resources if they were available to them. EHOs could use this information to

target specific groups, such as females, and tailor information for them in establishments that they may most likely visit.

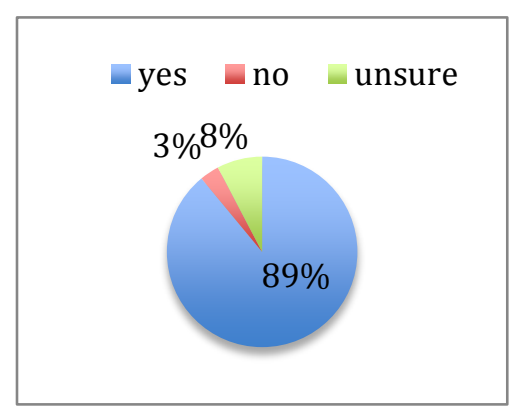

As discussed in the literature review, the field is still underdeveloped with minimal regulations, which may not be extensive enough when considering the potential for contamination and disease with invasive procedures. Studies that have looked into the knowledge of workers in the industry demonstrate major inconsistencies in compliance in sanitation and education about communicable diseases (Asif \& Ahmad, 2011). Environmental Health Officers and governments could use studies of this nature to help when determining what the public thinks and wants from their public health inspectors in personal service

establishments. It is clear from the results, that the public is interested in this subject area and would like more information. Studies have recommended that there be public health promotion regarding communicable disease transmission from PSEs, which reaches out to the workers in the industry. In addition, they recommend that the public become empowered to inquire about the safety themselves before undergoing a procedure (Asif \& Ahmad, 2011). As of right now, both parties, the public and the industry workers, should be taking precautions and understanding the risks involved in invasive procedures of this kind. The regulations still have potential for development, and if input from the public, EHOs and industry workers are taken into consideration the most effective regulations could be developed. Studies that have found that there needs to be training in infection control in PSEs, agree that regulations need to be developed in the field (Johnson et at., 2001). Regulation development will take time, but public education and empowerment can be done separately and faster than legislative development.

The inconsistencies in employee knowledge and training can be a major cause of public health concern. Employees are performing 
invasive procedures and putting the public at risk by their lack of knowledge, creating opportunities where a blood borne pathogen could be transferred between clients through "routine" procedures (Harris-Roberts et al., 2013). This study found that $49 \%$ of respondents said they "sometimes" felt at risk due to a personal service. This number may be able to be lowered in the future, if the public were armed with information to help them find an establishment they trust because they have taken proper precautions in finding well-trained, responsible employees. EHOs can make efforts to educate the public about how they can protect themselves and make informed choices. EHOs can also work with the industry to make the required information more accessible to the public, opening communication and improving public health.

\section{Recommendations}

The study can be used as a tool for public health inspectors in the PSE field. People are unclear about how regulated the industry is, and due to that might not take precautions that they should. Participants also are eager for more resources about health and safety in PSEs as shown by the descriptive data with $89 \%$ of participants requesting more information. EHOs could use studies like this as a starting point to determine what information would be most useful and how to deliver that information to the public.

EHOs could use information taken from studies and make suggestions in the PSE field. For example, most people responded that they never ask for references or sanitation procedures (58\% and 56\% respectively). People may not be inclined to ask because it may seem out of the ordinary or like too much of a hassle. If establishments were more open with clients in terms of their training/qualifications and provided this type of information, more people may utilize it. If people were armed with correct and complete information they could make informed decisions based on health and safety and not be swayed by price, appearance of an establishment, proximity to their home or any other factor.

\section{Limitations}

The study could have been improved by using a different population and possibly a different means of distributing the survey. If a paper survey was produced and locations were chosen with a random set of people were used, the results may be different. More responses could have been generated if more time was available for the researcher to collect data. Another method or population that could have been used was people coming from PSEs. A researcher could hand out questionnaires to people who are entering or leaving an establishment. This would ensure they fit the inclusion criteria and would be a random population.

Another way to improve this study would be to add a question regarding which type of personal service a respondent has had done in the past. This could help to exclude people who may not have had a procedure done and get further insight into which type of establishments most people were referring to when answering the questions. In addition, the Environmental Health students could have been excluded due to their additional insight into PSEs and risks involved.

\section{Possible Errors or bias}

There were some areas where this study might have shown a bias and resulted in possible errors in the results. The population that was used was somewhat limited to whom the survey reached through social media. Contacts who sent it to their contacts through a snowball effect may have friends in similar fields and backgrounds who may produce similar responses. In addition, the peer group of the researcher responded to the questionnaire, and this group of Environmental Health students have additional information in this subject area (especially in regards to question one which asked about how regulated the respondent thought the personal service establishment industry was). This group of people would all have most likely responded as "minimally regulated" which was taught in a course in this program.

\section{Future Research}

This study focused on asking participants questions regarding the extent of precautions they take at PSEs and their awareness. It did not however look into the reasons why or why they did not take the precautions. In addition, since the majority of participants showed confidence in their ability to recognize unsafe behaviors, an interesting study could test their knowledge on what an unhygienic practice would actually be to determine if their perceived ability is equivalent to their actual ability. Finally, an additional survey could ask expand on the finding that the majority of people are interested in additional information and determine what kind of information is being requested by individuals.

\section{Conclusions}

It was found that there were six statistically significant associations. An association existed between age and how regulated the participant thought the industry was, with over 30 year olds choosing minimally regulated. Associations existed between education and if participants ask about sanitation procedures before an appointment, and if participants asked for references before procedures, both with higher education backgrounds being more likely to ask. An association existed between gender and if participants felt they could recognize bad practices during a procedure, with females feeling more able. In addition, participants with some post secondary education felt they were more able to recognize bad practices during a procedure. The last association that was found was between gender and if additional information would be beneficial, with females showing more interest. EHOs can utilize information in studies similar to this to determine how to develop regulations and how they can educate the public with the information they are seeking.

\section{Acknowledgments:}

The production of this document was made possible due to the guidance and instruction from the BCIT Environmental Health instructors and additional support from students.

\section{Competing Interest:}

"The authors declare that they have no competing interest." 


\section{References}

Asif, S., \& Ahmad, F. (2011). Hepatitis C at work place: a survey of occupational health and safety knowledge and practice in beauty therapy industry. Gomal Journal Of Medical Sciences, 9(1), 6-10.

British Columbia Ministry of Health (2013). Guidelines for personal service establishments. Retrieved from http://www.health.gov.bc.ca/protect/pdf/pse-guidelines.pdf establishments in North York. Canadian Journal of Public Health.92(2),134-7.

Kluger, N. N., Terru, D. D., \& Godreuil, S. S. (2011). Bacteriological and fungal survey of commercial tattoo inks used in daily practice in a tattoo parlor. Journal Of The European Academy Of Dermatology \& Venereology, 25(10), 12301231. doi:10.1111/j.1468-3083.2010.03788.x

British Columbia Ministry of Health (1999). Guidelines for tattooingLeBlanc, P. M., Hollinger, K. A., \& Klontz, K. C. (2012). Tattoo inkRetrieved from http://www.health.gov.bc.ca/library/publications/year/1997/t attoo.pdf related infections -- awareness, diagnosis, reporting, and prevention. New England Journal Of Medicine, 367(11), 985-987. doi:10.1056/NEJMp1206063

British Columbia Ministry of Health (n.d.). Personal Service Establishments (PSEs). Retrieved from http://www.health.gov.bc.ca/protect/ehp_pse.html

BeautySafe (n.d.). Retrieved from http://www.beautysafe.ca.

Cegolon, L., Miatto, E., Bortolotto, M., Benetton, M., Mazzoleni, F., \& Mastrangelo, G. (2010). Body piercing and tattoo: awareness of health related risks among 4,277 Italian secondary school adolescents. BMC Public Health, 1073-80.
Microsoft Corporation. (2011). Microsoft ® Excel ® 2011.

Oberdorfer, A., Wiggers, J. H., Considine, R. J., Bowman, J., \& Cockburn, J. (2003). Skin penetration operators' knowledge and attitudes towards infection control. American Journal of Health Behavior, 27(2), 125

Public Health Act, R.S.B.C. c 28 (2008). Retrieved from http://www.bclaws.ca/EPLibraries/bclaws_new/document/I D/freeside/00_08028_01
Cosmetologists Act, R.S.B.C. с 178 (1996). Retrieved from http://www.bclaws.ca/Recon/document/ID/freeside/00_9617 8REP 01.

Deschesnes, M., Demers, S., Fines, P., (2006). Prevalence and characteristics of body piercing and tattooing among high school students. Canadian Journal of Public Health 97(4). Rodríguez-Blanco, I., Fernández, L., Peñaranda, J., del Molino, M., Retrieved from http://journal.cpha.ca/index.php/cjph/article/viewFile/750/75 0

Facebook. (2013). Retrieved from facebook.com

Garland, S. M., Ung, L., Vujovic, O. V., \& Said, J. M. (2006). Cosmetic tattooing: a potential transmission route for HIV?. Australian \& New Zealand Journal Of Obstetrics \& Gynaecology, 46(5), 458-459. doi:10.1111/j.1479828X.2006.00635.X

Google Docs. (2013). Retrieved from docs.google.com

Harris-Roberts, J., Bowen, J., Sumner, J., \& Fishwick, D. (2013). Health and safety inspection of hairdressing and nail salons by local authority environmental health practitioners. Journal Of Environmental Health, 75(6), 96-101.

Heacock, H., Sidhu, B. (2013a) Module 4 Research Design and Data Collection. ENVH 8400 Research Methods Manual. Burnaby, BC: British Columbia Institute of Technology.

Heacock, H., Sidhu, B. (2013b) Module 5 Descriptive Statistics. ENVH 8400 Research Methods Manual. Burnaby, BC: British Columbia Institute of Technology.

Heacock, H., Sidhu, B. (2013c) Module 5 Inferential Statistics. ENVH 8400 Research Methods Manual. Burnaby, BC: British Columbia Institute of Technology.

Hintz, J. (2013) NCSS 9. NCSS, LLC. Kaysville, Utah USA. wWw.ncss.com

Johnson IL, Dwyer JJ, Rusen ID, Shahin R, Yaffe B. (2001). Survey of infection control procedures at manicure and pedicure
Rideout, K. (2010) Comparision guidelines and regulatory frameworks for personal service establishments. Retrieved from

http://www.ncceh.ca/sites/default/files/PSE_Guidelines_Co mparison_Table_July\%202010.pdf chelonae infection associated with tattoos. Acta DermatoVenereologica, 91(1), 61-62. doi:10.2340/00015555-1034

Siavash J., Buxton J.A., Afshar, K., Copes, R., Baharlou, S. (2012) Tattooing and risk of Hepatitis B: A systematic review and meta-analysis. Canadian Journal of Public Health, 103(3). Retrieved from journal.cpha.ca/index.php/cjph/article/download/3039/2624

Superbug Outbreaks Linked to Unlicensed Tattooing. (2006). Clinical Infectious Diseases, 43(5), iii.

Vugia, D. J., Jang, Y., Zizek, C., Ely, J., Winthrop, K. L., \& Desmond, E. (2005). Mycobacteria in nail salon whirlpool footbaths, California. Emerging Infectious Diseases, 11(4), 616-618.

Winthrop, K. L., Albridge, K., South, D., Albrecht, P., Abrams, M., Samuel, M. C., \& ... Vugia, D. J. (2004). The clinical management and outcome of nail salon--acquired mycobacterium fortuitum skin infection. Clinical Infectious Diseases, 38(1), 38-44. 